\title{
HOMO DIGITALIS: GOVERNO E CONSTRUÇÃO DE SUBJETIVIDADES EM UM MUNDO DIGITAL
}

HOMO DIGITALIS: GOVERNMENT AND CONSTRUCTION OF SUBJECTIVITIES IN

A DIGITAL WORLD

\author{
RONE ELEANDRO SANTOS ${ }^{1}$ \\ Instituto Federal Sudeste de Minas Gerais - Brasil \\ rone.res@live.com
}

\begin{abstract}
RESUMO: Partindo do viés determinista da tecnologia veremos que esta tem poder suficiente para estabelecer formas-de-vida específicas, configurar a atividade humana, estruturar os comportamentos individuais e coletivos para produzir resultados desejados - entre estes está a construção condicionada e controlada de sujeitos sob encomenda. A ideia de uma razão tecnológica que constrói subjetividades pré-determinadas liga-se à noção foucaultiana de governamentalidade: um poder que se exerce sobre um conjunto de indivíduos através da estruturação dos possíveis campos de ação. Exercer o poder sobre os outros implica em governar ações, administrar eventualidades, gerenciar possíveis riscos e perigos. Nesse sentido, buscamos analisar o papel desempenhado por uma crescente racionalidade de governo efetuada e gerida pelos algoritmos. Com o advento da internet foi possível coletar e armazenar dados sobre os mais diversos aspectos da vida dos indivíduos. Tal situação possibilitou a instalação de um tipo completamente novo de governo que age através da otimização algorítmica dos comportamentos, das relações sociais e da própria vida.
\end{abstract}

PALAVRAS-CHAVE: Governamentalidade Algorítmica. Mundo Digital. Subjetivação. Forma-de-Vida.

\begin{abstract}
Starting from the deterministic bias of technology we will see that it has sufficient power to establish specific forms-of-life, to shape human activity, to structure individual and collective behaviors to produce desired results -- among these is the conditioned and controlled construction of subjects on demand. The idea of a technological reason that constructs predetermined subjectivities has a connection with Foucault's notion of governmentality: a power that is exercised over a group of individuals through the structuring of possible fields of action. Exercising power over others involves governing actions, administering events, managing possible risks and dangers. In this sense, we seek to analyze the role played by a growing rationality of government effected and managed by the algorithms. With the advent of the internet, it was possible to collect and store data on the most diverse aspects of individuals' lives. This situation made possible the installation of a completely new type of government that acts through the algorithmic optimization of behaviors, social relations and life itself.
\end{abstract}

KEYWORDS: Algorithmic Governmentality. Digital World. Subjectivation. Form-of-Life.

\footnotetext{
${ }^{1}$ Mestre em Filosofia Social e Política pela Universidade Federal de Minas Gerais (UFMG) e professor de Filosofia no Instituto Federal de Educação, Ciência e Tecnologia do Sudeste de Minas Gerais (IF Sudeste MG), Campus Muriaé.
} 


\section{INTRODUÇÃO}

Em Signos, Máquinas, Subjetividades (2014) Maurizio Lazzarato afirma que a construção da subjetividade no capitalismo tem especificidades e modos específicos de funcionamento. Para embasar esta afirmação, ele cita Gilles Deleuze e Félix Guattari que ressaltaram que a subjetividade no capitalismo é produzida através de dois dispositivos: a sujeição social (assujettissement sociaux) e a servidão maquínica (asservissements machiniques). Existem diferenças e complementaridade entre estes dois dispositivos, mas é importante enfatizar que é na interseção entre eles que ocorre a produção da subjetividade (LAZZARATO, 2014, p. 18).

Ao nos equiparmos com uma subjetividade individual nos atribuímos uma identidade, uma nacionalidade, uma profissão, um sexo, etc. Nesse momento, a sujeição social produz e distribui papéis dentro e para a divisão social do trabalho (LAZZARATO, 2014, p. 27). Segundo a argumentação de Karl Marx, afirma Lazzarato, "a sujeição social é um processo de personificação das relações de capital, pois o 'capitalista' age como 'capital personificado', isto é, como uma função derivada dos fluxos de capitais” (LAZZARATO, 2014, p. 28). Analisando desse modo, o trabalhador da fábrica é o "trabalho personificado", assim como as "pessoas" individuais são pessoas sociais derivadas de quantificações abstratas concebidas em sociedade. Mas a sujeição social é uma das maneiras como o capitalismo age sobre nossa subjetividade. Associado à produção do sujeito ou de uma pessoa individuada se sobrepõe outro tipo de tratamento e apreensão da subjetividade efetuada em um processo de "servidão maquínica".

No dispositivo de servidão maquínica o indivíduo não é mais tomado como um "sujeito individuado", um "sujeito econômico" (capital humano, empresário de si mesmo, empreendedor), ou como um "cidadão". Ao contrário disso, Lazzarato diz que o indivíduo está mais para ser considerado como uma peça, uma engrenagem ou uma roda dentada que funciona e é colocada em funcionamento. O indivíduo nada mais é do que "uma parte componente do agenciamento 'empresa', do agenciamento 'sistema financeiro', do agenciamento mídia, do agenciamento 'Estado de bem-estar social' e de seus 'equipamentos coletivos' (escolas, hospitais, museus, teatros, televisão, internet, etc.)" (LAZZARATO, 2014, p. 28).

Ao esclarecer o conceito de servidão, tal como foi utilizado por Deleuze e Guattari, Lazzarato aponta que este foi tomado de empréstimo das áreas da Cibernética e da Ciência da Computação significando "pilotagem" ou "governo" dos componentes de um sistema.

Um sistema tecnológico subjuga ("governa" ou "pilota") variáveis (temperatura, pressão, força, velocidade, resultado, etc.) assegurando a coesão e o equilíbrio funcional do todo. A servidão é o modo de controle e regulação ("governo") de uma máquina social ou técnica, como uma fábrica, uma empresa ou um sistema de comunicações. Ela recoloca a "servidão humana" dos antigos sistemas imperiais (egípcio, chinês, etc.), e por conseguinte é um modo de comando, de regulação e de governo "assistido" pela 
tecnologia, constituindo, como tal, uma especificidade do capitalismo (LAZZARATO, 2014, p. 28-29).

Refletindo sobre os modos de produção de sujeitos Deleuze descreve quais os tipos de subjetividades são construídos e controlados pelo duplo dispositivo da sujeição social e da servidão maquínica. Enquanto na sujeição se produz indivíduos, na servidão "os indivíduos tornaram-se 'dividuais', divisíveis, e as massas tornaram-se amostras, dados, mercados ou 'bancos"' (DELEUZE, 1992, p. 222). Do lado da sujeição social ocorre a fabricação de sujeitos ligados a objetos externos (como máquinas, artefatos de comunicação, dinheiro, etc.) aos quais fazem uso e com os quais estabelecem interação. "Na sujeição, o indivíduo trabalha ou se comunica com outro sujeito individuado via uma máquina-objeto, que funciona como 'meio' ou mediação de sua ação ou uso" (LAZZARATO, 2014, p. 29). Já na servidão maquínica não ocorre o constrangimento via dualismos como sujeito/objeto, palavras/coisas ou natureza/cultura. Ao contrário do individual, o dividual não está em oposição às máquinas e não faz uso de um objeto externo. Existe uma relação de contiguidade entre o dividual e as máquinas, entre humanos e máquinas, onde tanto um quanto outro são meras partes recorrentes e intercambiáveis de um processo maior de produção, comunicação e consumo. Visto dessa forma - e se concebermos que são funções do sujeito "agir sobre" coisas e situações, e "fazer uso" de coisas e situações - não agimos mais ou fazemos uso de algo. Tomado como um "ser dividual" o ser humano acaba por se constituir como "entradas e saídas, inputs e outputs, pontos de conjunção ou disjunção nos processos econômicos, sociais ou comunicacionais geridos e governados pela servidão" (LAZZARATO, 2014, p. 29).

Incorporando e combinando ao conceito de governamentalidade de Michel Foucault as reflexões sobre a sujeição social e a servidão maquínica, certamente ocorreria um enriquecimento e expansão de nosso poder analítico. Na governamentalidade temos como pano de fundo o modelo primordial do poder pastoral exercido sobre indivíduos, ao qual devemos acrescentar um tipo diferente de poder e controle que não é desempenhado pelo Estado, mas por empresas privadas e agem sobre "dividuais". Mais do que um governo sobre sujeito individuais, a governamentalidade tem se tornado cada vez mais o governo sobre sujeitos dividuais. Essas transformações que direcionam para um governo maquínico e tecnológico podem ser exemplificados pelas transformações ocorridas no sistema de coleta de dados para produção, propaganda, venda e consumo de mercadorias.

Com o avanço da propaganda nos anos 1920 e, posteriormente, com o advento da televisão, uma máquina cada vez mais bemorganizada se desenvolveu, da qual o Google e o Facebook pode ser considerados o coroamento: imensos "bancos de dados" que funcionam como dispositivos de marketing. Eles reúnem, selecionam e vendem milhões de dados sobre nosso comportamento, aquisições, hábitos de leitura, filmes favoritos, gostos, roupas e preferências de comida, assim como sobre o modo como passamos nosso "tempo livre". Essas informações concernem os "dividuais", cujos perfis, compostos pelo cruzamento desses 
dados, são meros relés de entradas e saídas, de inputs e outputs nas máquinas de produção-consumo. (LAZZARATO, 2014, p. 3738 , grifos do autor).

Os sujeitos dividuais possuem uma existência estatística controlada por dispositivos, que agem por operações diferentes daqueles que produzem sujeitos individuais - como os dispositivos colocados em funcionamento pelo poder pastoral que agem sobre indivíduos "reais". Uma governamentalidade de dividuais "gerenciada por fluxos, redes e máquinas, não apenas desempenha um papel nas representações do indivíduo e no comportamento consciente, mas em desejos, crenças e na realidade sub-representativa da subjetividade" (LAZZARATO, 2014, p. 28). Nesse sentido, podemos afirmar que a governamentalidade é praticada na junção e cruzamento do individual e do dividual, da sujeição social e da servidão maquínica.

É contra esta complementaridade entre os dispositivos de sujeição social e servidão maquínica, que delineiam as novas formas de governo, que temos de pensar um novo modo de ação e organização social e política. Somente assim será possível iniciar um processo de subjetivação independente e autônomo da dominação capitalista da subjetividade - presentes de forma intensa no mundo digital e no governo algorítmico -, a fim se constituir outras formas-de-vida não dependentes de um processo de digitalização da existência. Pensando nisso, buscamos estruturar este texto em quatro partes. Na primeira, analisaremos duas visões contrárias dentro da Filosofia da Tecnologia quanto ao avanço tecnológico: o instrumentalismo e o determinismo. Nesse momento, e tomando o viés determinista, veremos que a tecnologia tem poder suficiente para estabelecer formas-de-vida específicas, configurar a atividade humana, estruturar os comportamentos individuais e coletivos para produzir resultados desejados. O objetivo desejado é apontar que a tecnologia tem como meta a construção condicionada e controlada de sujeitos sob encomenda. Na segunda parte, veremos como a ideia de uma razão tecnológica que constrói subjetividades prédeterminadas está em consonância com a noção foucaultiana de governamentalidade: um poder que se exerce sobre um conjunto de indivíduos através da estruturação dos possíveis campos de ação. O exercício do poder sobre os outros implica no governo das ações, na administração das eventualidades, e no gerenciamento de possíveis riscos e perigos. Na terceira parte, buscamos analisar o papel desempenhado por uma crescente racionalidade de governo efetuada e gerida pelos algoritmos. Para tanto, veremos como a partir da criação e disseminação da internet - e com ela a progressiva digitalização da vida privada e das interações sociais - foi possível coletar e armazenar quantidades inimagináveis de dados sobre os mais diversos aspectos da vida dos indivíduos. Tendo em vista este cenário, temos como objetivo verificar e apontar a ocorrência de um processo de instalação de um tipo completamente novo de governo que age através da otimização algorítmica dos comportamentos, das relações sociais e da própria vida. Por fim, na quarte e última parte, realizamos algumas considerações críticas no sentido de questionar a racionalidade e governamentalidade algorítmica. Defendemos no final do texto a urgência e a necessidade de investigar o papel 
desempenhado pela racionalidade de governo efetuada e gerida pelos algoritmos, de tal modo que estes podem ser tomados, certamente, como um exemplar de dispositivo de servidão maquínica.

\title{
1 DeterminISMO IECNOLÓGICO E FORMA-DE-VIDA
}

O processo acelerado de avanço tecnológico impõe a necessária discussão sobre os impactos das mais diversas tecnologias. Nas discussões realizadas acerca da tecnologia podemos destacar duas visões opostas. Uma, denominada instrumentalismo tecnológico, que se caracteriza por um otimismo que afirma enfaticamente a existência de um progresso constante e de um crescimento intenso do conhecimento, devido ao desenvolvimento da tecnologia enquanto ferramenta que satisfaz nossas carências e necessidades (FEENBERG, 2013, p. 58). A outra é o determinismo tecnológico que "alude-se à ideia de que a tecnologia constitui uma força que governa, de algum modo, a sociedade e dirige seu rumo" (CUPANI, 2013 , p. 201). O determinismo tem como fundamento o pressuposto de que as tecnologias têm uma lógica de funcionamento explicável sem referência à sociedade. Nesse sentido, Andrew Feenberg afirma que a tecnologia é presumivelmente social apenas pelo propósito que serve, sendo que propósitos são elementos existentes na mente do observador. A tecnologia possui, então, uma semelhança com a ciência e a matemática por sua "independência intrínseca do mundo social'. Contudo, diferentemente da ciência e da matemática, a tecnologia tem poderosos e imediatos impactos sociais (apud FEENBERG, in.: SCHARFF \& DUSEK, 2014, p. 707-708).

Sendo capaz de governar, podemos então dizer que a tecnologia é autônoma? Essa questão da autonomia da tecnologia foi investigada por autores como Langdon Winner no seu livro Autonomous technology (1977). Nesta obra ele reconhece e compreende os ataques recebidos pela ideia de que a tecnologia seja autônoma, sobretudo pelos que salientam que a tecnologia responde sempre aos grupos de poder. Nesse sentido Winner assinala o parentesco da ciência e da tecnologia com a política porque, em ambos os casos, o foco central está nas fontes e no exercício do poder. A tecnologia é fonte de preocupações porque, na sua evolução, ela muda e provoca mudanças de uma maneira que parece eludir controles.

\begin{abstract}
O paradoxo desse processo é que experimentamos uma sorte de inércia da tecnologia juntamente com o sentimento de que nós, como indivíduos, tomamos decisões com relação à tecnologia (por exemplo, adotamos ou não um determinado aparelho); e supomos que as elites de poder também as tomam, ao incentivar, financiar ou rejeitar invenções (CUPANI, 2013, p.214).
\end{abstract}

Winner concorda com a ideia de um "auto aumento" da tecnologia, que avança como uma maré indefinida de invenções, às quais o conjunto da 
humanidade deve se adaptar seja com maior ou menor esforço. Nesse sentido, impõe-se a necessidade de pensar como a tecnologia determina a sociedade. ${ }^{2}$

Em um sentido fundamental, determinar coisas é aquilo a que se reduz a tecnologia. Se ela não fosse determinante, não teria utilidade e seria certamente de pouco interesse. O conceito "determinar" em seu sentido mundano sugere dar direção a, decidir o curso de, estabelecer, definitivamente, a forma ou configuração de algo. A primeira função de toda tecnologia - e a imediata condição da sua utilidade - é dar uma forma definida, artificial, a um conjunto de materiais ou a uma atividade humana específica. Um aparelho é uma estrutura de partes materiais reunidas de modo a produzir resultados determinados, previsíveis, quando colocada em operação. Uma técnica é uma estrutura do comportamento humano projetada para gerar determinado produto. Uma organização técnica é um conjunto de seres humanos e aparelhos em relações estruturadas, projetada para produzir certos resultados específicos. Uma operação técnica, na medida em que a pessoa se engaja nela, determina o que a pessoa faz. Se a operação é bem-sucedida, podese dizer que a tecnologia determinou o resultado. Isso não significa que a tecnologia ou os seus resultados sejam rígidos ou inflexíveis. O que indica é que a tecnologia triunfa através da conquista da desordem e da imposição de forma. (WINNER, 1977, p. 75, grifos e tradução nossa).

Em "Technologies as Forms of Life" Winner lamenta que em algum momento os métodos de avaliação da tecnologia usados pelos cientistas sociais tendiam a ver a mudança tecnológica como "causa" e tudo o que se segue dela como um "efeito" ou "impacto". Desse modo, caberia ao pesquisador apenas identificar, observar e explicar esses efeitos. Por outro lado, destaca uma versão mais prospectiva de avaliação da tecnologia usada para prever quais mudanças provavelmente acontecerão e, de posse destas previsões a sociedade está capacitada para traçar seus rumos. Não obstante estas duas maneiras de analisar a tecnologia, Winner ressalta uma visão analítica da tecnologia que supera as falhas empíricas e morais dos modelos de causa e efeito. Uma análise assim feita

[...] começa com o reconhecimento de que à medida que as tecnologias estão sendo construídas e colocadas em uso, já estão ocorrendo alterações significativas nos padrões de atividade humana e instituições humanas. Novos mundos estão sendo feitos. Não há nada "secundário" sobre esse fenômeno. É, de fato, a realização mais importante de qualquer nova tecnologia. A construção de um sistema técnico que envolve os seres humanos como partes operacionais traz uma reconstrução dos papéis e relações sociais. Muitas vezes isso é resultado de um novo sistema de requisitos operacionais próprios: ele simplesmente não vai funcionar a menos que o comportamento humano mude para se adequar à sua forma e processo. Portanto, o próprio ato de usar os tipos de máquinas, técnicas e sistemas disponíveis gera padrões de atividades e expectativas que logo se tornam uma "segunda natureza". Nós realmente "usamos" telefones, automóveis, luzes

${ }^{2}$ Feenberg ressalta que a visão determinista da tecnologia é comum no mundo dos negócios e na esfera governamental. Áreas onde muitas vezes se assume que o progresso é uma força exógena influenciando a sociedade em vez de uma expressão de mudanças na cultura (apud FEENBERG, in.: SCHARFF \& DUSEK, 2014, p. 708). 
elétricas e computadores no sentido convencional. Mas nosso mundo logo se torna um mundo em que a telefonia, a automobilidade, a iluminação elétrica e a computação são formasde-vida no sentido mais poderoso: a vida dificilmente seria pensável sem elas" (WINNER, 2004, p. 108, grifos e tradução nossa).

O conceito de "forma-de-vida" utilizado por Winner foi apropriado da elaboração feita por Ludwig Wittgenstein na obra Investigações Filosóficas. Apontando para os ricos e múltiplos tipos de expressões ou "jogos de linguagem" que fazem parte do discurso cotidiano, Wittgenstein enfatiza que "falar uma língua parte de uma atividade ou de uma forma-de-vida" (WITTGENSTEIN, 2009, p. 27). Para exemplificar o que afirma o filósofo apresenta uma série de exemplos como dar ordens, especular sobre eventos, adivinhar enigmas, inventar histórias, formar e testar hipóteses, e assim por diante, para indicar a ampla gama de jogos de linguagem envolvidos em diversas "formas-de-vida". Pode-se debater se ele quis sustentar que esses padrões ocorrem naturalmente para todos os seres humanos ou são convenções culturais que podem mudar com o tempo e o contexto. Contudo, para os interesses defendidos por Winner não importa o status filosófico fundamental do conceito wittgensteiniano. O que interessa é o que é sugestionado através do conceito: a superação da concepção difundida e extremamente estreita de nossa compreensão normal do significado da tecnologia na vida humana.

À medida que os dispositivos, artefatos, técnicas e sistemas tecnológicos se tornam parte da textura de nossa existência cotidiana suas qualidades de ferramentas são por nós incorporadas de modo a se tornarem parte de nossa própria humanidade. Somos seres que trabalham em nossos empregos, falam em telefones, se informam na internet, comem alimentos processados, limpam suas casas com produtos químicos, etc. Obviamente, trabalhar, falar, se informar, comer, limpar e outras ações há muito tempo fazem parte da atividade humana. Entretanto, "as inovações tecnológicas podem alterar radicalmente esses padrões comuns e, ocasionalmente, gerar novos, muitas vezes com resultados surpreendentes" (WINNER, 2004, p. 108, tradução nossa).

Nesse sentido, podemos afirmar que a maioria das mudanças no conteúdo da vida cotidiana provocada pela tecnologia pode ser reconhecida como versões de padrões de atividades humanas anteriores. Mas apesar disso, e por causa disso, Winner salienta a importância de levantar questões como: se de fato existem onde as tecnologias modernas adicionaram atividades fundamentalmente novas à variedade de coisas que os seres humanos fazem e já faziam? Onde e como as inovações na ciência e na tecnologia começaram a alterar as próprias condições de vida? A programação de computadores é apenas uma poderosa recombinação de formas-de-vida conhecidas há muito tempo - fazendo matemática, listando, classificando, planejando, organizando, etc. - ou é algo sem precedentes? (WINNER, 2004, p. 109, tradução nossa).

Certamente existem diferenças significativas entre pessoas e computadores. As "formas-de-vida" que dominávamos antes do advento do computador, do universo digital e algorítmico, moldaram nossas expectativas quando começamos 
a usar estes instrumentos e dispositivos. É verdade que nem toda inovação tecnológica incorpora escolhas com grande significado. Alguns desenvolvimentos tecnológicos são mais ou menos inócuos e criam apenas modificações triviais na forma como vivemos. Apesar disso, se ocorrem mudanças substanciais no que as pessoas fazem, se existem alterações profundas no modo de vida social, é necessário perguntar antecipadamente sobre as qualidades dos artefatos, das instituições e das experiências humanas.

Pensada pelo viés determinista a tecnologia tem o poder suficiente para estabelecer formas, direcionar uma ação, configurar a atividade humana, estruturar os comportamentos individuais e coletivos para produzir resultados desejados. $\mathrm{O}$ objetivo desejado com a tecnologia em sua vertente determinista é o da construção condicionada e controlada de sujeitos sob encomenda. Ora, esta ideia de uma razão tecnológica que constrói subjetividades pré-determinadas está em consonância com a noção foucaultiana de governamentalidade que é tomada como um poder que se exerce sobre um conjunto de indivíduos através da estruturação dos possíveis campos de ação.

\section{A gOVERNAMENTALIDADE EM Michel Foucault}

Para responder satisfatoriamente o que é o conceito/noção de governamentalidade 3 para Foucault, é preciso antes afirmar que ela sofreu modificações e acréscimos à medida que suas pesquisas foram avançando. Em consonância com os dois eixos da noção de governo - entendida ora como relação entre sujeitos, ora como relação consigo mesmo -, este filósofo apresenta duas ideias de governamentalidade, presentes em dois momentos de sua investigação. Em primeiro lugar, no âmbito da análise política quando Foucault afirma que este conceito/noção deve ser entendido através de três interpretações distintas, porém interligadas, que descrevem antes de tudo

\footnotetext{
${ }^{3}$ Traduzida do original gouvernamentalité, esta palavra inexiste tanto nos principais dicionários de língua francesa quanto no vernáculo lusitano. Em português, esta palavra é ora traduzida por governabilidade, ora por governamentalidade, o que pode resultar em confusões conceituais e de entendimento. Alfredo da Veiga-Neto, em seu artigo Coisas de Governo..., faz a defesa do uso de governamentalidade e não governabilidade como melhor tradução para a palavra do original francês. Segundo este autor enquanto governabilidade "denota a qualidade daquele ou daquilo que se pode governar ou que se deixa governar, que é dócil, que é obediente” (VEIGA-NETO, 2002, p. 12), governamentalidade seria mais adequado ao conceito gouvernementalité cunhado por Foucault,posto que essa tradução é vista como a "qualidade segundo a qual o Estado foi se tornando governamental" (VEIGA-NETO, 2002, p. 15). Para Veiga-Neto, é preferível fazer uso do conceito governamentalidade porque este faz referência mais às questões governamentais ligadas ao surgimento do Estado Moderno do que propriamente a alguma coisa ou alguém que pode ser objeto de um processo de governo ou direção porque é dócil e obediente. Curiosamente, na tradução inglesa de gouvernamentalité, não foi utilizada a palavra governableness, já existente no dicionário, mas o conceito governmentality. Por ser um termo que facilita a compreensão das sutis diferenças existentes entre governo no sentido político e governo no sentido de condução e direção de coisas ou pessoas Veiga-Neto conclama, junto a governamentalidade, a "ressurreição" da palavra governamento em língua portuguesa com o intuito de "tornar mais rigoroso e mais fácil o duplo entendimento que, na perspectiva foucaultiana, é possível atribuir à palavra governo" (VEIGANETO, 2002, p. 17). De fato, a adoção e uso destes termos não carregariam mais ainda a língua portuguesa, mas contribuiria para seu enriquecimento visto sua minuciosa elaboração e significativa aplicação.
} 
[...] o conjunto constituído pelas instituições, os procedimentos, análises e reflexões, os cálculos e as táticas que permitem exercer essa forma bem específica, embora muito complexa, de poder que tem por alvo principal a população, por principal forma de saber a economia política e por instrumento técnico essencial os dispositivos de segurança. Em segundo lugar, por "governamentalidade" entendo a tendência, a linha de força que, em todo o Ocidente, não parou de conduzir, e desde há muito, para a preeminência desse tipo de poder que podemos chamar de "governo" sobre todos os outros - soberania, disciplina - e que trouxe, por um lado, o desenvolvimento de toda uma série de aparelhos específicos de governo [e, por outro lado], o desenvolvimento de toda uma série de saberes. Enfim, por "governamentalidade", creio que se deveria entender o processo, ou antes, o resultado do processo pelo qual o Estado de Justiça da Idade Média, que nos séculos XV e XVI se tornou o Estado administrativo, viu-se pouco a pouco "governamentalizado". (FOUCAULT, 2008, p. 143-144, grifos do autor).

Nesse caso, trata-se daquilo que Edgardo Castro chamou de "governamentalidade política" (CASTRO, 2009, p. 191), e que foi desenvolvida nos cursos Segurança, Território, População (1977-1978) e Nascimento da Biopolítica (1978-1979). Em um segundo momento - e já no campo da análise ética -, Foucault define a governamentalidade de modo distinto, posto que agora seria pensada tendo por base a relação do sujeito consigo mesmo. Desse modo, em entrevista a Helmut Becker, Raúl Fornet-Betancourt e Alfred Gomez-Müller datada de 1984, Foucault explica que

[...] a governabilidade ${ }^{4}$ implica a relação de si consigo mesmo, o que significa justamente que, nessa noção de governabilidade, viso ao conjunto das práticas pelas quais é possível constituir, definir, organizar, instrumentalizar as estratégias que os indivíduos, em sua liberdade, podem ter uns em relação aos outros. São indivíduos livres que tentam controlar, determinar, delimitar a liberdade dos outros e, para fazê-lo, dispõem de certos instrumentos para governar os outros. Isso se fundamenta então na liberdade, na relação de si consigo mesmo e na relação com o outro. Ao passo que, se você tenta analisar o poder não a partir da liberdade, das estratégias e da governabilidade, mas a partir da instituição política, só poderá encarar o sujeito como sujeito de direito. Temos um sujeito que era dotado de direitos ou que não o era e que, pela instituição da sociedade política, recebeu ou perdeu direitos: através disso, somos remetidos a uma concepção jurídica do sujeito. Em contrapartida, a noção de governabilidade permite, acredito, fazer valer a liberdade do sujeito e a relação com os outros, ou seja, o que constitui a própria matéria da ética. (FOUCAULT, 2006, p. 286). ${ }^{5}$

\footnotetext{
${ }^{4}$ A palavra "governabilidade" aqui é apresentada pelos tradutores como tradução do termo original "gouvernementalitê". Entretanto, continuamos afirmando nossa posição de acatar a palavra "governamentalidade" como a melhor tradução para a expressão originalmente cunhada por Foucault, conforme as razões já aduzidas anteriormente (ver nota 2).

${ }^{5}$ Dois anos antes, na aula de 17/02/1982 do curso A hermenêutica do sujeito, Foucault já havia se expressado de forma semelhante: “(...) se considerarmos a questão do poder, do poder político, situando-a na questão mais geral da governamentalidade - entendida a governamentalidade como
} 
Para Foucault, o desenvolvimento da governamentalidade remonta muito mais longe no tempo e lança raízes na formação e no funcionamento da arcaica noção de pastorado. A pastoral, principalmente aquela criada e reelaborada pelo Cristianismo, constitui como que o pano de fundo de todo o fenômeno de governamentalização do Estado. De fato, como bem aponta Inês Lacerda Araújo, com o intuito de

[...] compreender como surge e como funciona o biopoder, Foucault recua na história até o poder pastoral, cuja genealogia remonta às primeiras civilizações orientais. E essa análise o leva até as noções mais atuais de governamentalidade e de conduta de toda uma população, na qual surge um novo tipo de subjetivação, e cujo solo é o liberalismo. O liberalismo é visto como o pano de fundo da biopolítica e é uma consequência da "arte de governar" dos séculos XVI e XVII que vai até meados do século XVIII, quando se transforma pela ação de um novo jogo, o da economia política, próprio do liberalismo. O interessante é que Foucault não cumpre a promessa de analisar o biopoder, pois se detém em uma acurada análise do poder pastoral, da razão de Estado e do liberalismo, mas não nessa ordem (ARAÚJO, 2009, p. 43).

Em suma, podemos ficar com a definição sintética de governamentalidade estabelecida por Foucault no seminário Technologies of the self apresentado na Universidade de Vermont em 1982: "Chamo 'governamentalidade' o encontro entre as técnicas de dominação exercidas sobre os outros e as técnicas de si” (FOUCAULT, 1988, p. 19). Nessa ocasião Foucault afirmou que cada vez mais se interessava pela interação operada entre o governo de si e o governo dos outros, pelas técnicas de dominação individual e pelo modo como um indivíduo age sobre si mesmo através das técnicas de si. É importante ressaltar que essa dominação é exercida por meio de uma relação de poder consentida - quer seja de uns sobre os outros ou de si sobre si mesmo - que requer também no consentimento e estímulo de que os sujeitos ajam sempre com liberdade. Em O sujeito e o poder Foucault afirma:

um campo estratégico de relações de poder, no sentido mais amplo do termo, e não meramente político, entendida, pois, como um campo estratégico de relações de poder no que elas têm de móvel, transformável, reversível -, então, a reflexão sobre a noção de governamentalidade, penso eu, não pode deixar de passar, teórica e praticamente, pelo âmbito de um sujeito que seria definido pela relação de si para consigo. Enquanto a teoria do poder político como instituição refere-se, ordinariamente, a uma concepção jurídica do sujeito de direito, parece-me que a análise da governamentalidade - isto é, a análise do poder como conjunto de relações reversíveis - deve referir-se a uma ética do sujeito definido pela relação de si para consigo. Isto significa muito simplesmente que, no tipo de análise que desde algum tempo busco lhes propor, devemos considerar que relações de poder/governamentalidade/governo de si e dos outros/relação de si para consigo compõem uma cadeia, uma trama e que é em torno destas noções que se pode, a meu ver, articular a questão da política e a questão da ética" (FOUCAULT, 2004, p. 306-307). Em outubro deste mesmo ano, em uma série de conferências na Universidade de Vermont, Foucault aponta para a confluência entre as práticas de "governamentalidade política" e as práticas de "governamentalidade ético-política" ao afirmar brevemente que chama governamentalidade "ao encontro entre as técnicas de dominação exercidas sobre os outros e as técnicas de si" (FOUCAULT, 1994, p. 784). Para Edgardo Castro é este estudo das relações entre o governo dos outros e o governo de si que, no marco da governamentalidade, permitirá a articulação das estratégias de resistência (CASTRO, 2009, p. 191). Sobre o lugar da resistência em Foucault remeto aqui a SAMPAIO, Simone Sobral. Foucault e a resistência. Goiânia: Editora da UFG, 2006. 
Quando definimos o exercício do poder como um modo de ação sobre ações dos outros, quando as caracterizamos pelo "governo" dos homens, uns pelos outros - no sentido mais extenso da palavra, incluímos um elemento importante: a liberdade. O poder só se exerce sobre "sujeitos livres", enquanto "livres" - entendendo-se por isso sujeitos individuais ou coletivos que têm diante de si um campo de possibilidade onde diversas condutas, diversas reações e diversos modos de comportamento podem acontecer. (FOUCAULT, 1995, p. 244).

Apesar de Foucault tomar com ressalva o termo "conduta" no texto anteriormente citado enfatiza ser ele o que melhor esclarece o que existe de específico nas relações de poder. A "conduta" cumpre duas funções visto que é ou "O ato de conduzir os outros (segundo mecanismos de coerção mais ou menos estritos)", ou "a maneira de se comportar num campo mais ou menos aberto de possibilidades" (FOUCAULT, 1995, p. 244). Exercer o poder sobre os outros é menos da ordem do cerceamento, do afrontamento entre adversários e do impedimento através de mecanismos legais e mais da ordem do governo das ações, da administração das eventualidades, da gestão dos possíveis riscos e perigos.

Este desejo de gerenciar o acaso, e tudo que diz respeito ao campo do imprevisível, aumentou progressivamente à medida que as ações governamentais passaram, cada vez mais, a serem pautadas e decididas pelo conhecimento estatístico. Entre os mais significativos trabalhos que se dedicaram ao estudo de um "governo pelos números" podemos citar aqueles empreendidos por Alain Desrosières e Alain Supiot. ${ }^{6}$ O aparecimento dos computadores, a criação da internet, o crescimento exponencial do conjunto de dados digitais (concentrados no Big Data) e o uso generalizado dos algoritmos acabou por potencializar ainda mais a aspiração por antecipar os problemas e predizer comportamentos.

Fundamentada no conceito foucaultiano de governamentalidade, Antoinette Rouvroy, professora na Université de Namur e pesquisadora no Centre de Recherche en Information, Droit et Société (CRIDS), tem se dedicado ao estudo da nova configuração entre saberes e poderes no universo do Big Data. Suas análises a levaram ao desenvolvimento do conceito de "governamentalidade algorítmica" que ela toma como um desdobramento da governamentalidade neoliberal.

\section{GOVERNO ALGORÍtMICO E CONSTRUÇÃO DE SUBJETIVIDADES}

Em parceria com seus colegas de trabalho Thomas Berns (Université Libre de Bruxelles) e Dominique Depris (Université Catholique de Louvain), Antoinette Rouvroy realizou a retomada do conceito de governamentalidade forjado por Foucault. Suas pesquisas têm o objetivo de buscar comprovar a ideia de que atualmente está em processo a instalação de um tipo completamente novo de governamentalidade que não se fundamenta tanto na lei ou na disciplina, mas

\footnotetext{
${ }^{6}$ Sobre o governo pelos números conferir: DESROSIÈRES, Alain. Gouverner par les nombres. Paris: Presses de l'Ecole des Mines, 2008; SUPIOT, Alain. La Gouvernance par les nombres: cours au Collège de France (2012-1014). Paris: Fayard, 2015.
} 
sobre a otimização algorítmica dos comportamentos, das relações sociais e da própria vida dos indivíduos. Com efeito, a especificidade da governamentalidade algorítmica, segundo Rouvroy, reside no fato de que se baseia não mais sobre normas impostas pelo Estado. Seu fundamento está nos inúmeros vestígios numéricos de nossas atitudes e comportamentos que constantemente proliferam no mundo digital da internet (muitas vezes, e em geral, sem o nosso conhecimento).

[Trata-se de] um modo de governo alimentado essencialmente por dados brutos (que operam como sinais infra-pessoais e asignificantes mas quantificáveis); que afetam os indivíduos sob o modo de alerta, provocando o reflexo, mais do que sob o modo da autorização, proibição ou persuasão, ao se apoiar sobre suas capacidades de entendimento e de vontade; visando essencialmente a antecipar o futuro, a limitar o possível, muito mais do que regulamentar as condutas. Os dispositivos da governamentalidade algorítmica integram o datamining: a exploração das reservas de dados massivos e brutos, que individualmente não possuem nenhum sentido, para a partir deles traçar perfis de comportamento. $O$ datamining permite gerir as pessoas de maneira personalizante, industrial, sistemática e preemptiva, se interessando por elas somente enquanto pertencentes a uma multitude de perfis (de consumidores, de delinquentes potenciais, etc) (ROUVROY, 2014, p. 5, tradução nossa).

Aqui vemos, em linhas gerais, um esboço dos principais pontos que devem ser analisados para o entendimento da governamentalidade algorítmica. O ponto de partida e a matéria-prima de todo planejamento e ação desta maneira de governar passa antes de tudo pelo imenso conjunto de dados digitais que formam o Big Data. A recente e vertiginosa proliferação dos dados numéricos tem conduzido a uma radical mudança na maneira como estatisticamente eles são tratados.

A análise estatística clássica buscou desde seu surgimento observar, classificar e analisar fenômenos coletivos ou de massa (finalidade descritiva) para, enfim, "investigar a possibilidade de fazer inferências indutivas válidas a partir dos dados observados e buscar métodos capazes de permitir esta inferência (finalidade indutiva)" (BERQUÓ, 2001, p. 7-8). Ela vem realizando uma categorização a priori dos dados a serem tratados. Esta categorização é sempre realizada por seres humanos a partir de suas representações do mundo. Sendo assim, estas representações são sempre distorcidas de modo a não poder reivindicar ser mais do que uma aproximação da realidade. Pensada nestes moldes a estatística não chega a resultados baseada apenas em uma pretensa objetividade dos dados e números. Nesta composição da realidade entram outros elementos que são acrescentados pelos estatísticos a partir de suas percepções, experiências e vivências que não estão presentes no conjunto de números. Ao contrário da estatística clássica a governamentalidade algorítmica opera através de três grandes momentos: a coleta massiva de dados (dataveillance), o tratamento e mineração de dados (datamining) e ação sobre os comportamentos via criação de perfis 
(profiling). Estas etapas permitem o funcionamento da governamentalidade algorítmica, ao mesmo tempo em que impossibilitam toda interpretação dos fenômenos, representação do mundo e construção de subjetividades que não sejam condicionadas.

Embora se trate de um problema relevante e de grande impacto as discussões sobre a incidência das tecnologias digitais demandam uma ampliação das iniciativas de pesquisa e investigação sobre suas técnicas de atuação. Diversos estudos têm sido realizados sobre como as Tecnologias de Informação e Comunicação (TIC) estão provocando mudanças comportamentais na sociedade. Trata-se de uma "nova maneira de produzir conhecimentos sobre atitudes preferenciais futuras, comportamentos ou eventos sem considerar as motivações psicológicas, os discursos ou as narrativas do sujeito, mas sim com base em dados" (ROUVROY, 2013, p. 113). A lógica algorítmica dispensa o indivíduo do ônus e da responsabilidade de transcrever, interpretar e avaliar os eventos do mundo. As consequências disso podem ser vistas, por exemplo, no descompromisso com a verdade e na proliferação da mentira como regra. O que é feito através do redirecionamento do debate político da esfera pública para a esfera privada de grupos fechados onde circulam mensagens criptografadas com informações duvidosas.

$\mathrm{Na}$ abertura do livro La vie algorithmique: critique de la raison numérique (2015) Éric Sadin descreve um dia qualquer na vida de uma pessoa comum que tem sua rotina profundamente mediada por algoritmos de todo tipo, com funções e finalidades diferenciadas. O leitor dessa descrição feita por Sadin pode perceber três aspectos da relação do sujeito descrito com os dispositivos de uso doméstico, com os de meios de transporte e de comunicação, e com os espaços da cidade e do trabalho. O primeiro consiste no incremento de sensores em um vasto conjunto de aparelhos que são capazes de recolher informações do mundo ao seu redor. O segundo diz respeito à colocação e ligação de todos estes dispositivos em rede. Por último, é possível observar diferentes efeitos oriundos deste processo de captação e compartilhamento de dados resultantes de mediações algorítmicas cujo funcionamento e operacionalidade são desconhecidas. Para exemplificar o que diz o autor descreve o sistema de reconhecimento facial automatizado. Esta ferramenta permite ou não a entrada do indivíduo em seu local de trabalho, faz a captura de sua temperatura e, a partir de uma vasta base de dados, pode diagnosticar (para o poder público ou para a indústria farmacêutica) a iminência de um quadro depressivo ou de uma epidemia de gripe, muito antes de ocorrerem efetivamente. Não obstante o tom de ficção científica que pode ser atribuído ao texto de abertura, a descrição centrada na mediação algorítmica/tecnológica do cotidiano feita por Sadin descortina o panorama social para o qual o filósofo destina seu diagnóstico e sua crítica da razão digital. O mérito do estudo empreendido em La vie algorithmique está na acessibilidade das descrições e análises de um cenário tecnológico onde operam os algoritmos.

O modo como ocorre o funcionamento do dispositivo tecnológico algorítmico possibilita o que Sadin denomina de tecno-poder. Este consiste em uma nova e abrangente forma do poder centrado nas indústrias de tratamento 
massivo de dados que detêm uma inédita potência de governo sobre os homens e as sociedades.7 "Além de interferirem no cotidiano e nos 'estilos de vida', as tecnologias digitais sob a forma de objetos e sistemas programados pelo tecnopoder chegam a organizar os quadros perceptivos e as ações humanas" (JÚNIOR, 2015, p.260). Atrelado a isso, pode-se afirmar que Sadin realiza a contraposição entre o seu conceito de tecno-poder à asserção foucaultiana de que "o poder está por toda a parte", a partir da alegação de que "não somente o poder não está por toda a parte, mas sua fonte, seu coração, pode ser hoje precisamente localizada: eles se situam nos laboratórios de pesquisa animados pelos sonhos sem limites dos engenheiros" (SADIN, 2015, p. 203). Apesar de usar demasiadamente a prioris ideológicos e não levar em consideração nem mesmo a ação de figuras importantes como Edward Snowden, que contrariam o julgamento de que o tecno-poder emana de centros de pesquisa das empresas do Vale do Silício a análise de Sadin tem sua importância. ${ }^{8}$

Após mais de um século de expansão da racionalidade funcionalista e das técnicas computacionais estamos em um momento em que elas atingiram seu auge "impondo uma razão numérica fundada sobre uma divisão e uma memorização de todos os atos da vida" (SADIN, 2015, p.261). Cada vez mais aceitamos ser governados por este sistema que se intensifica e se aperfeiçoa a uma velocidade tamanha que não damos conta de assimilar. Será que estamos decididos a empreender uma oposição a esta lógica digital com base em outros fundamentos que possam favorecer a faculdade humana de livre escolha e construção consciente de nossas existências e subjetividades? Para Sadin, este é um desafio decisivo e prático que definirá nossa natureza individual e coletiva no presente e os rumos futuros da humanidade. Mais do que nunca é necessário continuamente analisar a determinação efetuada na conformação do mundo e de nossas experiências realizadas pelas tecnologias digitais. Este talvez seja um passo importante para, senão barrar pelo menos repensar, o indefinidamente grande alcance das técnicas de governo algorítmico. Esta é a razão pela qual a politização das múltiplas escalas de nossas relações com as tecnologias numéricas reenvia, em última análise, para a questão da forma-de-vida que desejamos adotar, e para a necessária vigilância que devemos manter sobre os sistemas robotizados que cada vez mais configuram nossas existências. A submissão da vida algorítmica contemporânea e da razão numérica a uma crítica torna-se cada vez mais urgente. Atualmente, - e sem menosprezar os vários outros problemas urgentes que precisam ser resolvidos, como a questão climática -, este é um dos mais relevantes campos de combate político, ético e civilizacional.

\footnotetext{
7 É possível detectar semelhanças entre o conceito de tecno-poder tal como elaborado por Éric Sadin e o conceito de governamentalidade algorítmica pensado por Antoinette Rouvroy. Todos os dois partem de um conjunto de dados brutos que, após serem trabalhados, fornecem conhecimentos suficientes para antecipar, direcionar e configurar comportamentos futuros. Resumindo: trata-se da instalação de um sistema de "behaviorismo de dados" implementado pelas empresas de tecnologia em nossa sociedade cada vez mais digitalizada.

${ }^{8}$ Para saber mais da visão de Sadin sobre as empresas baseadas na tecnologia digital - como Google, Apple, Facebook, Uber, Netflix e outras -, do chamado Vale do Silício, podemos recorrer ao seu livro La Silicolonisation du Monde: l'irrésistible expansion du Libéralisme Numérique (2016).
} 


\section{CONSIDERAÇÕES FINAIS}

Para direcionar uma conclusão do presente estudo sobre as implicações dos algoritmos como instrumento e tecnologia de formação de subjetividades, podemos levantar os seguintes questionamentos: existe um condicionamento efetuado pelos algoritmos na construção da personalidade e subjetividade dos indivíduos? De que modo a filtragem de dados/informações e a construção de bolhas digitais fechadas e direcionadas reduzem ou mesmo eliminam o debate, a discordância e o confronto com as diferenças? Qual a correlação deste mundo digital construído sob medida com a produção de opiniões radicais e a fragilização das experiências comuns? Qual o papel desempenhado pelos criadores e desenvolvedores de programas e códigos algorítmicos? Eles podem ser responsabilizados pela construção enviesada do mundo e dos sujeitos realizada por meio dos algoritmos?

Partimos da hipótese de que com o Big Data e o amplo uso de algoritmos, importa muito mais a objetividade fornecida pelos próprios dados - e as correlações feitas entre eles - que são tomadas como expressão dos fenômenos e eventos reais. Mais do que isso, como o conjunto de dados coletados é imenso, estes dizem, definem e apresentam, tal como são, o mundo e as pessoas. Tomada dessa forma, é reduzida toda intervenção humana e dispensado o uso de convenções prévias, representações e interpretações, esquivando-se das subjetividades e das normas discursivas. O que não significa desconsiderar as normas sociais e as intervenções humanas embutidas nos programas, máquinas e tecnologias digitais de relações humanas (redes sociais). Isso porque mesmo que se tornem cada vez mais "autônomas" e "inteligentes", as máquinas dependem de seu design inicial, das intenções e dos cenários em função dos quais elas foram construídas. Em última instância as máquinas, programas e tecnologias digitais são, desde sua concepção, portadoras de visões de mundo, expectativas, projeções conscientes ou inconscientes de seus criadores.

Diante do exposto justifica-se a urgência e o imperativo de tomar como objeto de investigação o papel desempenhado pela racionalidade de governo efetuada e gerida pelos algoritmos. Para retomar Winner é preciso que prestemos atenção não somente à fabricação de instrumentos físicos e processos - embora isso seja importante -, mas também para a produção de condições psicológicas, sociais e políticas como parte de qualquer mudança técnica significativa. Iremos conceber e construir circunstâncias que aumentem as possibilidades de crescimento da liberdade humana, da sociabilidade, da inteligência, da criatividade e autogoverno, ou estamos construindo algo extremamente diferente disso? (WINNER, 2004, p. 112).

Nesse sentido, a política possui uma tarefa fundamental. À medida em que a imaginação política confronta a tecnologia como forma-de-vida, deve ser capaz de dizer algo sobre as escolhas, implícitas ou explícitas, feitas no decorrer da inovação tecnológica, bem como discernir os fundamentos para fazer essas escolhas com sabedoria. Através da criação tecnológica, afirma Winner, construímos um mundo para vivermos e para os outros viverem (WINNER, 2004, 
p.112). Resta sabermos refletir com clareza sobre como usamos o universo digital e admitir nossa responsabilidade pelo que estamos fazendo.

\section{REFERÊNCIAS}

ARAÚJO, Inês Lacerda. Foucault, para além de Vigiar e Punir. Revista de Filosofia Aurora, v. 21, n. 28, Curitiba, p. 39-58, jan-jun, 2009.

BERQUÓ, Elza Salvatori; SOUZA, José Maria Pacheco; GOTLIEB, Sabina Léa Davidson. Bioestatística. 1aㅡ ed., 7aㅡ reimp. São Paulo: EPU, 2001.

CASTRO, Edgardo. Vocabulário de Foucault: um percurso pelos seus temas, conceitos e autores. Trad. Ingrid Müller Xavier. Belo Horizonte: Autêntica Editora, 2009.

CUPANI, Alberto. Filosofia da tecnologia: um convite. $2^{\underline{a}}$ ed. Florianópolis: Editora da UFSC, 2013.

DELEUZE, Gilles. Post-scriptum sobre as sociedades de controle. In: Conversações: 1972-1990. Tradução de Peter Pál Pelbart. Rio de Janeiro: Editora 34, 1992.

FEENBERG, Andrew. Democratic Rationalization: Technology, Power, and Freedom. In: SCHARFF, Robert C.; DUSEK, Val (eds.). Philosophy of Technology: the Technological Condition: na anthology. Second Edition. Walden, MA and Oxford: John Wiley \& Sons, Inc., 2014. p. 706-719.

O que é a Filosofia da Tecnologia? In: NEDER, Ricardo Toledo (org.). A teoria crítica de Andrew Feenberg: racionalização democrática, poder e tecnologia. $2^{a}$ edição. Brasília: Observatório do Movimento pela Tecnologia Social na América Latina / CDS / Unb / Escola de Altos Estudos da CAPES, 2013. p.51-65.

FOUCAULT, Michel. Technologies of the Self. In: MARTIN, Luther; GUTMAN, Huck; HUTTON, Patrick (orgs.). Technologies of the Self: a seminar with Michel Foucault. Massachusetts: The University of Massachusetts Press, 1988. p.16-49.

Les techniques de soi. In.: Dits et Écrits. Vol. IV. Editado por D. Defert, F. Ewald \& J. Lagrange. Paris: Gallimard, 1994.

O sujeito e o poder. In: DREYFUS, Hubert; RABINOW, Paul. Michel Foucault, uma trajetória filosófica: para além do estruturalismo e da hermenêutica. Rio de Janeiro: Forense Universitária, 1995. p. 231-249.

A Hermenêutica do sujeito. Trad. Márcio Alves da Fonseca e Salma Tannus Muchail. São Paulo: Martins Fontes, 2004.

A Ética do cuidado de si como prática da liberdade. In.: Ditos e Escritos: Ética, Sexualidade, Política. Vol. V. $2^{a}$ ed. Tradução de Elisa Monteiro e Inês Autran Dourado Barbosa. Rio de Janeiro: Forense Universitária, 2006.

Segurança, Território, População. Curso dado no Collège de France (19771978). Trad. Eduardo Brandão. São Paulo: Martins Fontes, 2008. 
JÚNIOR, Ícaro Ferraz Vidal. Por uma teoria ética da técnica: a vida algorítmica segundo Éric Sadin. Revista Eco Pós. Dossiê Tecnopolíticas e Vigilância, v. 18, n. 2, Rio de Janeiro: UFRJ, p.254-260, 2015.

KAPLAN, David M. (ed.). Reading in the Philosophy of Technology. Lanham, MD: Rowman \& Littlefield, 2004.

LAZZARATO, Maurizio. Signos, Máquinas, Subjetividades. São Paulo: Edições SESC; São Paulo: N-1 Edições, 2014.

ROUVROY, Antoinette. The end(s) of critique: data behaviourism versus due process. In: HILDEBRANDT, Mireille; DE VRIES, Katja (eds.). Privacy, Due Process and the Computational Turn: The Philosophy of Law meets the Philosophy of Technology. Abingdon, Oxford, New York: Routledge, 2013. p.143-168.

.Le droit à la protection de l avie privée comme droit à un avenir non préoccupé, et comme condition de survenance du commun. (Draft / Version provisoite) Entretiens a propôs du droit a la protection de la vie privée (a paraitre). Ed. Claire Lobet-Maris, Nathalie Grandjean, Perrine Vanmeerbeek. Paris: FYP Editions, 2014. Disponível em: https://works.bepress.com/antoinette_rouvroy/53/. Acessado em : 16 maio 2019.

SADIN, Éric. La vie algorithmique: critique de la raison numérique. Paris: L'Echappee Editions, 2015.

SCHARFF, Robert C.; DUSEK, Val (eds.). Philosophy of Technology: the Technological Condition: na anthology. Second Edition. Walden, MA and Oxford: John Wiley \& Sons, Inc., 2014.

VEIGA-NETO, Alfredo. Coisas de governo... In.: RAGO, Margareth; ORLANDI, Luiz B. L.; VEIGA-NETO, Alfredo (org.). Imagens de Foucault e Deleuze: ressonâncias nietzscheanas. Rio de Janeiro: DP\&A, 2002. p.13-34.

WINNER, Langdon. Autonomous technology: technics-out-of-control as a theme in political thought. Cambridge: The MIT Press, 1977.

Technologies as Forms of Life. In: KAPLAN, David M. (ed.). Reading in the Philosophy of Technology. Lanham, MD: Rowman \& Littlefield, 2004. p. 103-113.

WITTGENSTEIN, Ludwig. Investigações Filosóficas. 6aㅡ ed. Petrópolis, RJ: Vozes, 2009.

Recebido em: 23-07-2019

Aceito para publicação em: 14-12-19 